\title{
Uluslararası Acil Durum Veri Tabanına Göre Türkiye Cumhuriyeti Tarihindeki Afetler
}

\author{
Hande Bahadır1, ${ }^{1, *}$ Reyhan Uçku² \\ ${ }^{1}$ Dokuz Eylül Üniversitesi, Tıp Fakültesi, Halk Sağı̆ğı Anabilim Dalı, İş ve Meslek Hastalıkları Bilim Dalı, 35340, İzmir. \\ ${ }^{2}$ Dokuz Eylül Üniversitesi, Tıp Fakültesi, Halk Sağlığı Anabilim Dalı, 35340, İzmir. \\ Özet
}

Uluslararası Acil Durum Veri Tabanı, doğal ve teknolojik afetlere yönelik 115 yıllık evrensel veriyi ücretsiz sunan bir veri tabanıdır. Bu çalışmada, Türkiye Cumhuriyeti'nin kuruluşundan 2016 yll sonuna kadar olan afetlerin dağllımlarl ve ölüm sayılarının araştırılması amaçlanmıştır. Tanımlayıcı tipte planlanan çalışmanın evrenini veri tabanında bulunan, 1923-2016 yılları arasında Türkiye'de meydana gelen afetler oluşturmuştur. Veri, SPSS 15.0 paket programı kullanılarak sıklık dağllımları olarak sunulmuştur. Veri tabanında $1923-2016$ yılları arasında Türkiye Cumhuriyeti sinırları içerisinde toplam 313 adet afete ait veri olduğu saptanmıştır. Meydana gelen 313 afetin $\% 51$ 'ini doğal afetler oluşturmaktadır. En fazla afet 2004 yılında, en fazla ölüm ise 1939 yılında gerçekleşmiştir. Depremler tüm afetlerin $\% 24.3$ 'ünü oluşturmakla birlikte, afetlerde yaşanan can kayıplarının \%90'ından fazlasindan sorumludur. Doğal ve önlenemez bir afet olarak kabul edilen deprem, alınan kişisel, çevresel, yapısal ve kentsel önlemlerle olumsuz sonuçların büyük ölçüde önlenebildiği bir afettir. Can kayıplarının önlenebilmesi için depreme dayanıklı binalarda yaşama teşvik edilmeli, kişisel ve çevresel riskler değerlendirilerek risk haritaları çıkarılmalı, depremden korunma eğitimleri arttırılmalıdır.

$\underline{\text { Anahtar Sözcükler }}$

EM-DAT, Doğal Afetler, Deprem, Türkiye

\section{Disasters in the Republic of Turkey According to the International Disaster Database}

\begin{abstract}
The Emergency Events Database is a free database containing 115 years' worth of data for natural and technological disasters. In this study, it is aimed to investigate the distribution of disasters and death figures from the foundation of the Republic of Turkey until the end of 2016. Disasters, which occurred in Turkey between 1923 and 2016 were included in this descriptive study. Data were analyzed using SPSS version 15.0 software and descriptive results were presented as frequency. 313 disasters were found in the database between the years 1923-2016 within the Turkish Republic borders. 51.1\% of them are natural disasters. The highest number of disasters occurred in 2004 while the highest death happened in 1939. Earthquakes constitute $24.3 \%$ of all disasters. The earthquake, which is considered as an unavoidable, is a disaster which can be largely prevented by personal, environmental, structural preventions. In order to avoid deaths, living in earthquake-resistance houses should be encouraged, personal and environmental risks should be assessed and protection trainings should be increased.
\end{abstract}

$\underline{\text { Keywords }}$

EM-DAT, Natural Disasters, Earthquake, Turkey

\section{Giriş}

Afet, "can ve mal kaybına, yaralanmalara, sakatlıklara ve olumsuz çevresel sonuçlara neden olarak, toplumu ekonomik ve sosyal yönden etkileyen, yerel kaynaklar ile üstesinden gelinemeyen, ulusal veya uluslararası yardıma gereksinimin duyulan, sıklıkla doğal nedenler ile oluşan ancak insan kaynaklı nedenlere bağlı olarak da gerçekleşebilen beklenmedik olay" olarak tanımlanmaktadır (EM-DAT 2017; UNISDR 2009; UNISDR 2015). Afetler bazı kaynaklarda gelişme hızı (ani gelişen/yavaş gelişen) veya ölçeğine (küçük ölçekli/büyük ölçekli) göre sınıflandırılmakla birlikte, sıklıkla şiddetli soğuk, kuraklık gibi yavaş gelişen doğal afetler; deprem, sel, kitle hareketi, heyelan gibi ani gelişen doğal afetler ve ulaşım kazaları, endüstriyel kazalar, savaşlar gibi teknolojik (insan kaynaklı) afetler olmak üzere iki ana başlıkta incelenmektedir (Işık vd. 2012).

* Sorumlu Yazar: Tel: +90 (232) 4124001 Faks: +90 (232) 4124023

E-posta: handebahadir86@gmail.com (Bahadır H), reyhan.ucku@deu.edu.tr (Uçku R)
Gönderim Tarihi / Received: 31/10/2017

Kabul Tarihi / Accepted : :09/01/2018 
Teknolojik (örn: patlamalar) ve insan kaynaklı (örn: ulaşım kazaları, savaşlar) afetlerin birbirinden kesin sınırlarla ayrıldığı yayınlar da vardır (Törenci 2015). Shaw vd. (2012) ise afetlerin doğal ve insan kaynaklı olmak üzere ikiye ayrıldığını ancak doğal ve kasıtsız insan kaynaklı afetlerin iş birliği ile meydana gelen çok yönlü afetlerin de giderek daha çok kabul edildiğini bildirmektedir. Bu çok yönlü afetler büyük bir insani krize dönüştüğünde ise karmaşık insani acil olarak adlandırılmaktadır (Shaw vd. 2012). Farklı kaynaklarda farklı sinıflamaların kullanılmasının nedeni afetlerin birbirinden kesin sinırlarla ayrılamaması, bazı insan davranışlarının doğal afetleri veya etkilerini arttırması, yine insan kaynaklı afetlerin bir bölümünü ise çevresel koşullarının arttırmasıdır.

Emergency Events Database (EM-DAT) yani Acil Durum Veri Tabanı, Belçika merkezli Afetlerin Epidemiyolojisi Araştırma Merkezi (The Centre for Research on the Epidemiology of Disasters - CRED) isimli kar amacı gütmeyen bir kuruluşun uluslararası veri tabanlarından biridir. Temel amaçları ulusal ve uluslararası düzeyde insani yardımı desteklemek, karar vericileri afet hazırlığı için örgütlemek ve kırılganlığı ve öncelikleri değerlendirmek için nesnel bir temel sağlamak olan EM-DAT doğal ve insan kaynaklı afetlere yönelik 115 yıllık evrensel veriyi ücretsiz olarak sunmaktadır. Bu veri tabanına göre bir olayın afet olarak sayılabilmesi için en az 10 kişinin ölmesi, en az 100 kişinin etkilenmesi, olağanüstü hal ilan edilmesi ve ilgili devlet tarafından uluslararası yardım çağrısı yapılması kriterlerinden en az biri gerçekleşmiş olmalıdır. EM-DAT veri tabanı Birleşmiş Milletler (BM) kuruluşları, sivil toplum örgütleri, sigorta şirketleri, araştırma kuruluşları ve medya gibi çeşitli kaynaklardan çaprazlama yapılarak derlenmektedir (EM-DAT 2017).

Dünyamız hemen hemen her gün doğal ya da teknolojik bir afetle karşı karşıya kalmaktadır ve bu afetler nedeniyle oluşacak zararların önlenmesi mümkündür (Varol 2007). Yaşanan afetlerin sıklık, dağılım ve değişimini incelemek, alınacak önlemlerin belirlenmesinde yol gösterici olmaktadır. Bu araştırmada uluslararası bir veri tabanı olan EM-DAT kullanılarak, coğrafi koşulları ve iklimi nedeniyle bir afet ülkesi olan, Türkiye Cumhuriyeti'nin kuruluşundan 2016 yılı sonuna kadar gerçekleşmiş afetlerin dağılımları ve ölüm sayılarının araştııılması amaçlanmıştır.

\section{Materyal ve Yöntem}

Tanımlayıcı tipte planlanan araştırma 2017 yılının Ağustos ayında EM-DAT veri tabanı kullanılarak yapılmışır. EM-DAT veri tabanındaki afetler başlıca doğal ve teknolojik afetler olarak ikiye ayrılmakta ve bu afetlerin altında bulunan alt gruplar Tablo 1'de gösterildiği gibi incelenmektedir (Guha-Sapir vd. 2017).

Tablo 1: EM-DAT veri tabanında kullanılan afet sınıflandırması

\begin{tabular}{|c|c|c|c|}
\hline \multicolumn{2}{|c|}{ Doğal Afetler } & \multicolumn{2}{|c|}{ Teknolojik Afetler } \\
\hline Afet alt grubu & Ana afet tipi & Afet alt grubu & Ana afet tipi \\
\hline \multirow{3}{*}{ Jeofiziksel } & Deprem & \multirow{7}{*}{ Endüstriyel kaza } & Kimyasal sızıntı \\
\hline & Kitle hareketi & & Çökme \\
\hline & Volkanik faaliyet & & Patlama \\
\hline \multirow{3}{*}{ Meteorolojik } & Aşırı Sicaklık & & Ateş \\
\hline & Sis & & Gaz sızıntıs1 \\
\hline & Firtına & & Zehirlenme \\
\hline \multirow{3}{*}{ Hidrolojik } & Sel & & Radyasyon \\
\hline & Heyelan & \multirow{4}{*}{ Ulaşım kazası } & Hava \\
\hline & Dalga hareketi & & Yol \\
\hline \multirow{3}{*}{ Klimatolojik } & Kuraklık & & Tren yolu \\
\hline & Buzul gölünün patlaması & & Deniz \\
\hline & Orman yangını & \multirow{4}{*}{ Çeşitli kazalar } & Çöküş \\
\hline \multirow{3}{*}{ Biyolojik } & Salgın & & Patlama \\
\hline & Böcek istilası & & Yangın \\
\hline & Hayvan kazası & & Diğer \\
\hline
\end{tabular}

Araştırmanın evrenini EM-DAT veri tabanında bulunan, 1923-2016 yılları arasında Türkiye'de meydana gelen doğal ve teknolojik afetler oluşturmuş, örnek seçimi yapılmadan tüm evrene ulaşılmıştır. Veri tabanından Türkiye'de gerçekleşen afetler seçilmiş, bu afetler gerçekleştikleri yil, afetin grubu (doğal veya teknolojik), afetin ana tipi (deprem, sel, yangın, salgın vd.) ve ölüm sayıları göz önüne alınarak SPSS programına işlenmiştir. Veri SPSS 15.0 paket programı kullanılarak sıklık dağılımları olarak sunulmuştur. 


\section{Bulgular}

EM-DAT veri tabanında 1923-2016 yılları arasında Türkiye Cumhuriyeti sınırları içerisinde toplam 313 afet olduğu saptanmıştır. Şekil 1'de görüldüğü üzere meydana gelen 313 afetin \%51,1'i (n=160) doğal, \%48,9'u (n=153) teknolojik afettir. Doğal afetlerin \%95,4'ü ani gelişen, \%4,6'sı ise yavaş gelişen tiptedir. Afetler alt gruplarına göre incelendiğinde \%35,8'i ulaşım kazası, \%28,4’ü jeofiziksel ve \%13,1'i hidrolojik alt grubundadır. Afetlerde yaşanan toplam can kayb1 91.797'dir. Şekil 2'de görüldüğü gibi can kayıplarının \%90'ından fazlası doğal afetler nedeniyle gerçekleşmiştir.

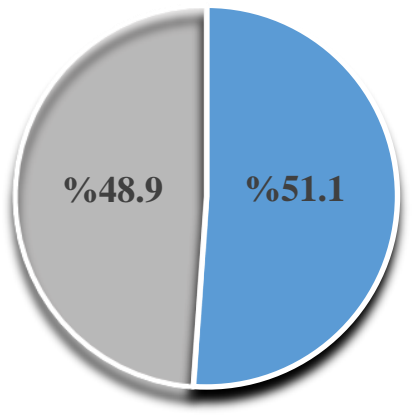

Şekil 1: Afetlerin gruplara göre gerçekleşme dağılımı
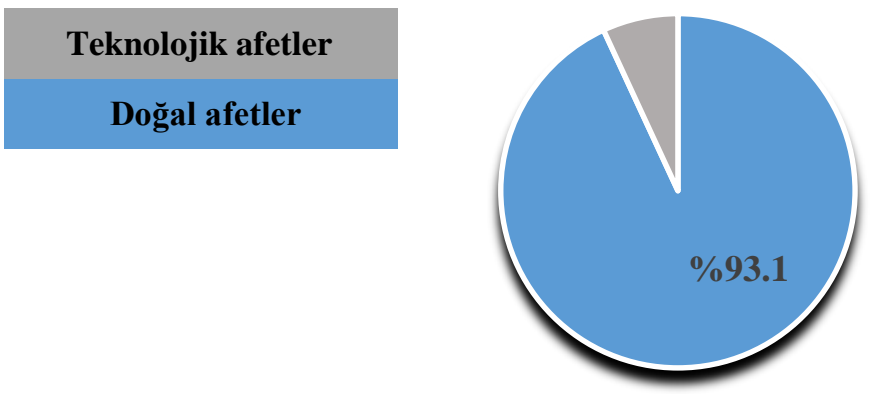

Şekil 2: Afet gruplarına göre can kayıplarının dağılımı

Şekil 3'de gösterildiği üzere, afetlerin \%24.3'ü deprem (n=76), \%20.8'i yol kazası (n=65), \%13.1'i sel baskını (n=41), \%9.6'sı deniz kazası $(n=30), \% 5.8$ 'i ise $(n=13)$ patlamadır. Daha sonra sıklığına göre sırasıyla kitle hareketi, firtına, hava kazası ve salgın gelmektedir. Depremler tüm afetlerin \%24.3'ünü oluşturmakla birlikte doğal afetlerin \%47.5'ini oluşturmaktadır.

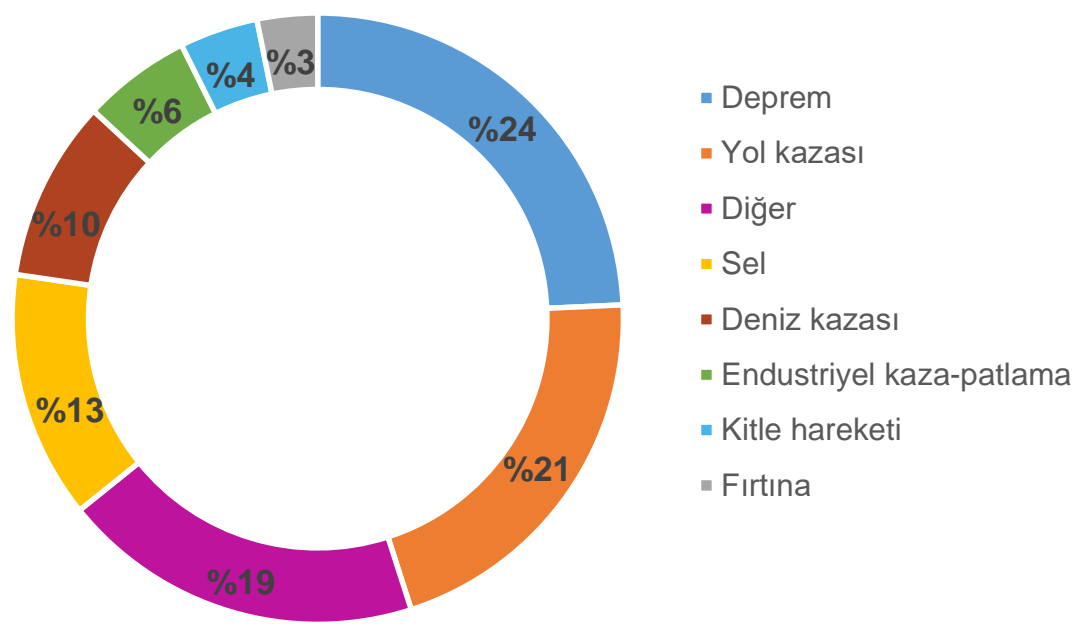

Şekil 3: Afetlerin tipine göre sıklık dağılımı

En fazla afet 2004 yılında, en fazla ölüm ise 1939 yılında gerçekleşmiştir. 1939 yılındaki yüksek ölüm oranına, Türkiye' de meydana gelen afetlerde gerçekleşen tüm can kayıplarının \%36'sına neden olan Erzincan Depremi'nin bu yıl gerçekleşmesi neden olmuştur. İkinci yüksek can kaybı ise 17.127 can kaybına neden olan Gölcük Depremi'nin etkisi ile 1999 y1lında gerçekleşmiştir. Şekil 4'de gösterildiği üzere, afetler dönemlere göre incelendiğinde düzenli bir artış izlenmekle birlikte, yaşanan can kayıplarında 1980-1998 dönemine kadar düzenli bir düşüş, bu dönemin sonunda ise yeniden yükselme görülmektedir. Depremlerin neden olduğu toplam can kaybı 82.574'dür ve bu sayı yaşanan can kayıplarının \%90’ından fazlasını oluşturmaktadır. Gerçekleşen tüm depremlerin \%80,3'ü ölümlüdür ve ölümlü depremlerin \%20'sinden fazlasında en az 1.000 kişi hayatını kaybetmiştir. 
Afet başına ölümler incelendiğinde yine depremlerin gerçekleşme başına neden olduğu 1.087 ölümle ilk sırada olduğu; arkasından sırasıyla çeşitli kazalar-yangın, salgın, çeşitli kazalar-patlama ve uçak kazasının geldiği görülmüştür (sırasıyla gerçekleşme başına neden oldukları ölüm sayısı 301, 77, 61, 55).

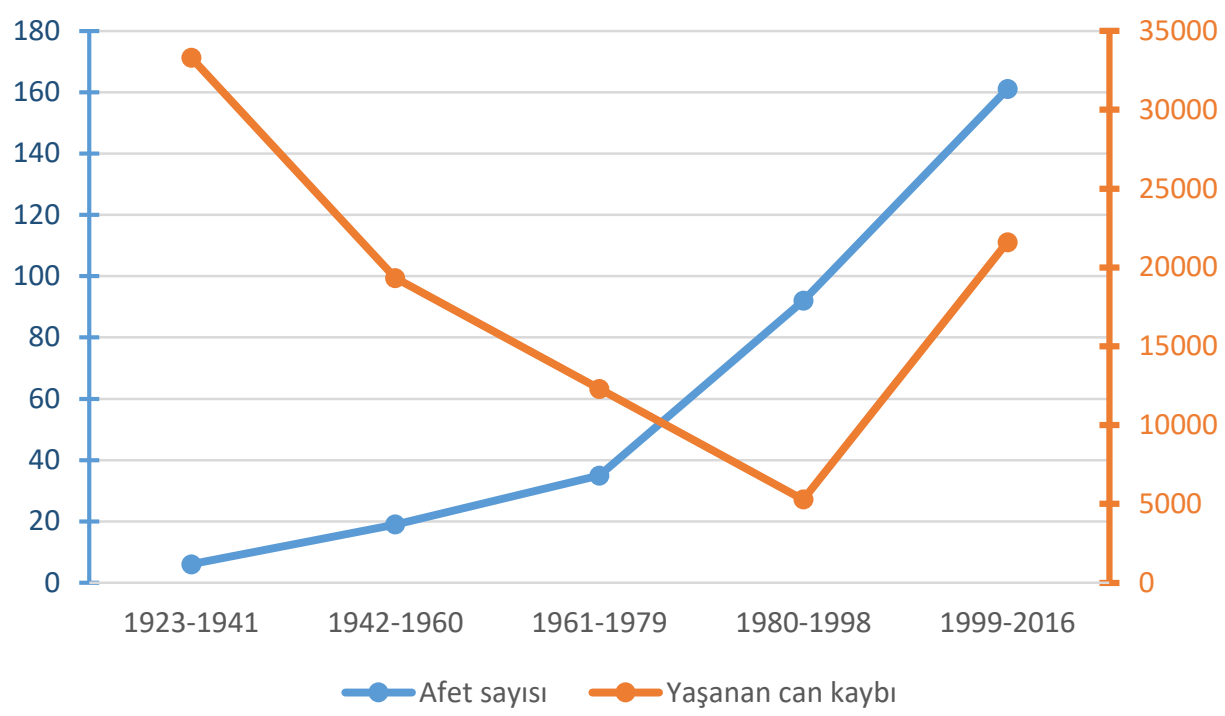

Şekil 4: Dönemlere göre afet sayıları ve afetlerde meydana gelen ölüm sayıları

Tablo 2'de dönemlere göre en sık görülen ilk üç afet tipi sıklıkları ile incelenmiştir. 1923-1941 döneminde meydana gelen afetlerin \%100'ünü depremler oluştururken, sonraki dönemlerde sırasıyla \%73,7, \%45,7 ve \%15,2'ye düşmüş, 1999-2016 döneminde ise \%16,8'e yükselmiştir. Doğal afetler 1923-1941 döneminde gerçekleşen afetlerin \%100'ünü oluştururken, oran sırasıyla \%94,8; \%80,0; \%41,3 olacak şekilde düşüş göstermiş, 1999-2016 döneminde yeniden \%43,5'e yükselmiştir. Ulaşım kazaları ilk defa 1980-1998 döneminde anlamlı yoğunluğa ulaşmış, yükseliş bir sonraki dönemde de devam etmiştir.

Tablo 2: Dönemlere göre en fazla görülen ilk üç afet ve sıklıkları

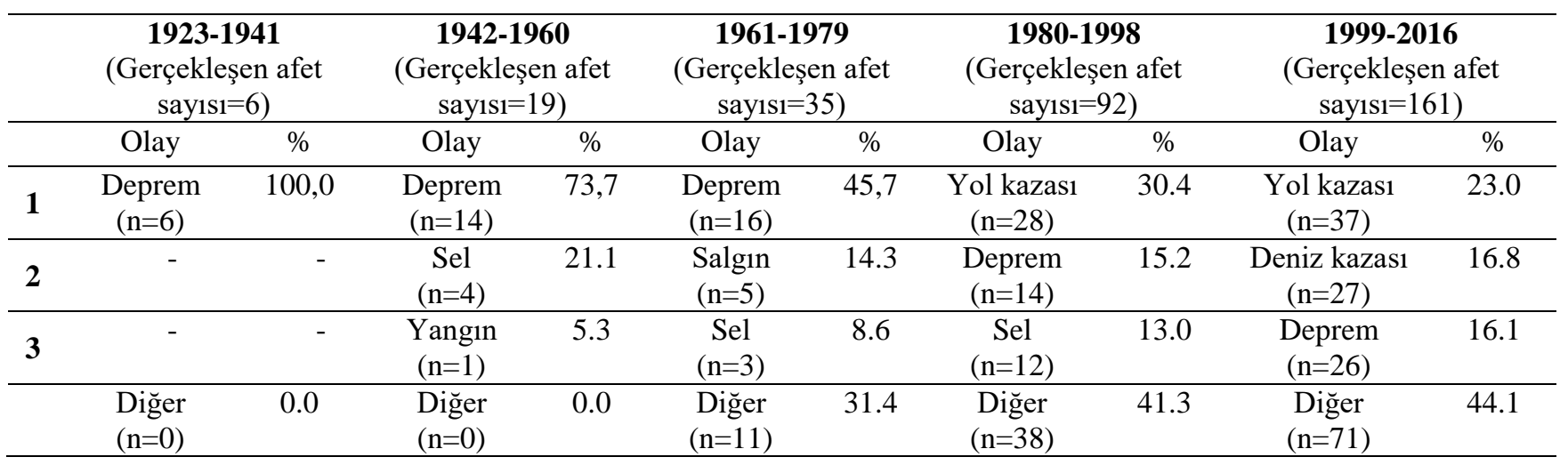

\section{Tartışma}

Türkiye Cumhuriyeti kurulduğu günden bu yana can kaybı, yaralanma ve maddi zarara yol açan afetlerle sık sık karşılaşılmıştır. Uluslararası Acil Durum Veri Tabanı kullanılarak Türkiye Cumhuriyeti'nin tarihindeki afetlerin incelendiği bu çalışmada, ülkemizi en sık etkileyen ve en fazla ölüme yol açan afet tipinin deprem olduğu görülmüştür. Bu durum Türkiye'nin, en aktif deprem kuşaklarından birisi olan, Alp-Himalaya deprem kuşağı içerisinde yer almasından kaynaklanmaktadır (Eyidoğan 2007). Dünya genelinde 2004-2013 yılları arasında sel problemi öne çıkmış ve en sık gözüken doğal afet olmuştur. Aynı dönemde depremler gerçekleşme sıklığı açısından tüm dünyada gerçekleşen doğal afetlerin \%7'sini oluşturmuşken, Türkiye bu dönemlerde ağırlıklı olarak ulaşım kazalarının etkisi altında kalmıştır. 
Depremler Türkiye'de gerçekleşen tüm afetlerin yaklaşık \%25'ini oluşturmakla birlikte, afetlerde yaşanan can kayıplarının \%90'ından fazlasından sorumludur. 2016 yılının sonuna kadar depremler Türkiye'de 82.000'den fazla bireyin yaşamını kaybetmesine neden olmuştur. Aynı dönem için Afet ve Acil Durum Yönetim Başkanlığı'nın (AFAD) verdiği ölüm sayısı 95.544 olup, sayılar arasındaki fark EM-DAT veri tabanının yalnızca afet tanımına uyan olayların verisini sunması ve iki veri tabanının göz önüne aldıkları kaynaklar olabilir (TABB 2017). Türkiye'de 1999 yılında gerçekleşen Gölcük depremi, neden olduğu 17.000'den fazla can kaybı ile son 20 yılda dünyada en yüksek sayıda ölüme neden olan 15 'inci doğal afet ve altıncı deprem olarak kayıtlara geçmiştir (CRED 2016). Dünyada 2004-2013 yılları arasında depremler doğal afetler nedeniyle gerçekleşmiş ölümlerin \%66,4'üne neden olmuștur. 1972-1996 yılları arasında dünyada meydana gelen afetlerde en fazla ölüme kuraklık neden olmuş, depremler ikinci sırada gelmiştir. Dünyayı etkisi altında bırakan kuraklık Türkiye'nin iklimsel özellikleri nedeniyle ön planda olmamıştır.

Çalışmada kullanılan EM-DAT veri tabanı verileri ile Devlet Su İşleri (DSI) Genel Müdürlüğü ve AFAD gibi kurumların verileri arasında farklılık olduğu gözlenmiştir. İlgili kaynaklar incelendiğinde, Türkiye'de yalnızca 1989-2012 yılları arasında 629 taşkının, 2015 yılında toplam 219 adet M>4.0 depremin meydana geldiği gözlenmiştir (Ersoy 2016). Çalışma için kullanılan veri tabanında bir olayın afet olarak sayılabilmesi için gerekli kriterlerin, sayısal anlamda bu farkı meydana getirdiği düşünülmektedir.

1996-2015 yılları arasında tüm dünyada ağırlıklı olarak jeofiziksel türde olmak üzere 7 binden fazla afet meydana gelmiş, özellikle klimatolojik ve meteorolojik afetlerde de ciddi artışlar gözlenmiştir (CRED 2016). Ülkemizde ise ilgili yıllarda teknolojik afetler ağırlık kazanmaya başlamıştır. Depremlerden sonra en sık gözüken doğal afet olan sel; iklim değişiklikleri, ormansızlaştırmanın neden olduğu erozyon ve hatalı insan faaliyetleri ile yakından ilişkilidir (Ergünay 2007).

Afetlerin zaman içindeki artışı, afet veri tabanlarının kurulması ve sonuç olarak küresel afetlerin kaydının ve afetlere erişimin kolaylaşması nedeniyle yanıltıcı bir artış olabilir. Aynı zamanda endüstrileşme, nüfus artışı, çarpık kentleşme ve iklim değişikliği artışın temel nedenleri olabilir. Dünyada 1970-2000 arası afetler incelendiğinde sayının üç katına çıktığı, etkilenen kişi sayısının artmakla birlikte ölümlerin azaldığı belirtilmektedir (CRED 2016). Afet hazırlık çalışmalarının yaygınlaştırılması, bu çalışmaların kamuya duyurulması ve halk sağlığı yanıtının güçlenmesi ölümlerin azalmasında etkili olmuş olabilir.

Genellikle uygun olmayan kalkınma politikalarının sonucunda gerçekleşen doğal afetler bu özelliği ile genellikle okuryazarlığın düşük olduğu, alt yapısı yetersiz gelişmekte olan, düşük gelirli ülkeleri daha sert etkilemektedir (Gökçe vd. 2008; WHO 2002). Hızlı nüfus artışı, düzensiz göçler, uygun olmayan yapılaşma ve şehirleşmenin yoğun olarak devam etmesi nedeniyle doğal afetlerin ve afet sonucunda meydana gelen ölüm, yaralanma ve maddi zararın azalması beklenemez (Ergünay 2007).

\section{Sonuç}

Uygun planlama politikaları, mühendislik önlemleri, erken uyarı sistemlerinden yararlanılması, afet bilincinin geliştirilmesine yönelik kamu kurumları, sivil toplum kuruluşları, üniversiteler ve medya işbirliğinin yapılması, çarpık kentleşmenin ve mümkün oldukça iklim değişikliğinin önlenmesi tüm afetlerin etkisini azaltmak için gereklidir. Doğal ve önlenemez bir afet olarak kabul edilen deprem, alınan kişisel, çevresel, yapısal ve kentsel önlemlerle ölümlerin büyük ölçüde önlenebildiği bir afettir. Can kayıplarının önlenebilmesi için depreme dayanıklı binalarda yaşama teşvik edilmeli, kişisel ve çevresel riskler değerlendirilerek risk haritaları çıkarılmalı, depremden korunma eğitimleri arttırılmalıdır.

\section{Kaynaklar}

CRED, (2016), Poverty \& Death: Disaster mortality 1996-2015, http://www.unisdr.org/files/50589_creddisastermortalityallfinalpdf.pdf, [Erişim 28 Ekim 2017].

EMDAT, (2017), The EM-DAT Glossary, http://www.emdat.be/glossary, [Erişim 11 Temmuz 2017].

Ergünay O,. (2007), Türkiye'nin afet profili, TMMOB Afet Sempozyumu Bildiri Kitabı'nın İçinde, Mattek Matbaacılık, Ankara, ss. 1-14. Ersoy Ş. (2016), 2015 yılının doğa kaynaklı afetleri, TMMOB Jeoloji Mühendisleri Odası Yayınları, Afşaroğlu Matbaacılık, Ankara.

Eyidoğan H., (2007), Marmara bölgesinin ve Istanbul kentinin deprem tehlikesi üzerine bir derleme, TMMOB Afet Sempozyumu Bildiri Kitabı'nın İçinde, Mattek Matbaacılık, Ankara ss. 15-29.

Guha-Sapir D., Below R., Hoyois P., (2017), EM-DAT: International Disaster Database, http://www.emdat.be, [Erişim 10 Haziran 2017].

Gökçe O., Özden Ş., Demir A., (2008), Türkiye’de Afetlerin Mekansal ve İstatistiksel Dağılımı Afet Bölgeleri Envanteri, T.C. Bayındırlık ve İskan Bakanlığı Afet İşleri Genel Müdürlüğü Afet Etüt ve Hasar Tespit Daire Başkanlı̆̆ı, https://www.afad.gov.tr/upload/Node/3491/xfiles/abep_kitap_matbaa_final_04122008_small.pdf, [Erişim 12 Ekim 2017].

Işık Ö., Aydınlığlu H.B., Koç S., Gündoğdu O., Korkmaz G., Ay A., (2012), Afet yönetimi ve afet odakll sağllk hizmetleri, Okmeydanı Tip Dergisi, 28(2), 82-123.

Shaw J.A., Espinel Z., Shultz J., (2012), Care of children exposed to the traumatic effects of disaster, American Pskyatric Publishing, Washington DC. 
TABB, (2017), Ölü sayısına göre raporlar, Türkiye Afet Bilgi Bankası, Afet ve Acil Durum Yönetimi Başkanlı̆̆1, https://tabbanaliz.afad.gov.tr/Genel/Raporlar.aspx, [Erişim 30 Ekim 2017].

Törenci H.E., (2015), Afet yönetimi ve Bursa'da sağllk sektöründe afet yönetimi, Yüksek Lisans Tezi, Beykent Üniversitesi, İstanbul, Türkiye.

UNISDR, (2009), UNISDR Terminology on Disaster Risk Reduction, The United Nations Office for Disaster Risk Reduction, http://www.unisdr.org/files/7817_UNISDRTerminologyEnglish.pdf, [Erişim 11 Ağustos 2017].

UNISDR, (2015), Updated Terminology on Disaster Risk Reduction: A Technical Review, The United Nations Office for Disaster Risk Reduction. http://www.unisdr.org/files/7817_UNISDRTerminologyEnglish.pdf, [Erişim 12 Ağustos 2017].

Varol N., (2007), Doğal ve teknolojik afetler konusunda toplumun bilinçlendirilmesi ve “AFEM'in” rolü, TMMOB Afet Sempozyumu Bildiri Kitabı'nın İçinde, Mattek Matbaacılık, Ankara ss. 127-131.

WHO, (2002), Disasters and Emergencies Definitions, http://apps.who.int/disasters/repo/7656.pdf, [Erişim 12 Temmuz 2017 ]. 